\title{
Y vein? Y not? The underdog of the composite arterial world
}

\author{
Saswata Deb, MD, and Stephen E. Fremes, MD
}

\footnotetext{
From the Schulich Heart Centre, Sunnybrook Health Sciences Centre, University of Toronto, Toronto Ontario Institute of Health Policy Management and Evaluation, University of Toronto, Toronto, Ontario, Canada. Disclosures: Authors have nothing to disclose with regard to commercial support.

Received for publication Aug 15, 2015; accepted for publication Aug 18, 2015; available ahead of print Sept 15, 2015.

Address for reprints: Stephen E. Fremes, MD, Dr Bernard S. Goldman Chair in Cardiovascular Surgery, University of Toronto, Schulich Heart Centre, Sunnybrook Health Sciences Centre, 2075 Bayview Ave, Room H405, Toronto, ON, Canada M4N 3M5 (E-mail: stephen.fremes@sunnybrook.ca).

J Thorac Cardiovasc Surg 2015;150:1195-7 $0022-5223 / \$ 36.00$

Copyright (C) 2015 by The American Association for Thoracic Surgery http://dx.doi.org/10.1016/j.jtcvs.2015.08.055
}

Despite growing evidence for arterial grafting in coronary artery bypass grafting surgery $(\mathrm{CABG}),{ }^{1,2}$ saphenous vein grafts (SVGs) still remain the most commonly used graft. ${ }^{3}$ This is likely due to the length of the venous conduit, availability, and ease of harvesting. In patients with severely calcified aortas or lack of conduits, composite Y grafting from the left internal thoracic artery (LITA) can be an important strategy to achieve more complete revascularization. ${ }^{4,5}$ Although composite grafting is typically used with arterial conduits, the use of the SVG as a $\mathrm{Y}$ from the internal thoracic artery is regarded as combining the "best and worst conduit" 6 and has not been well accepted to date. $^{5,7}$ To this end, Kim and colleagues ${ }^{8}$ conducted a randomized trial (SAVE RITA) that compared the SVG (harvested with an atraumatic no touch technique) with the right internal thoracic artery (RITA; harvested in a skeletonized fashion) as a composite Y-graft from the LITA in off-pump CABG with minimal aortic manipulation and reported that at 1-year, SVG was not inferior to RITA with respect to graft patency; clinical outcomes were also similar between the 2 groups at 1 and 4 years. Size mismatch between the LITA and SVG was minimized by using vein from the lower leg, as opposed to the thigh, and by avoidance of dilatation. A morphologic analysis by this group by means of intravascular ultrasonography and quantitative angiography of the SVGs of a subset of these patients showed that these SVGs underwent appropriate negative remodeling at 1 year. ${ }^{9}$ In this issue of the Journal, the investigators of the SAVE RITA trial report their conduct of a separate substudy to compare postoperative changes in serial nuclear studies between the SVG and RITA cohorts. ${ }^{10}$

More specifically, Hwang and colleagues ${ }^{10}$ investigated 116 patients ( $\mathrm{SVG}, \mathrm{n}=65$; RITA, $\mathrm{n}=51$ ) from the 224 patients $(51.8 \%)$ initially enrolled in the SAVE RITA trial; these patients had patent grafts at 1-year angiography and also underwent myocardial single photon emission computed tomography (SPECT) preoperatively and then

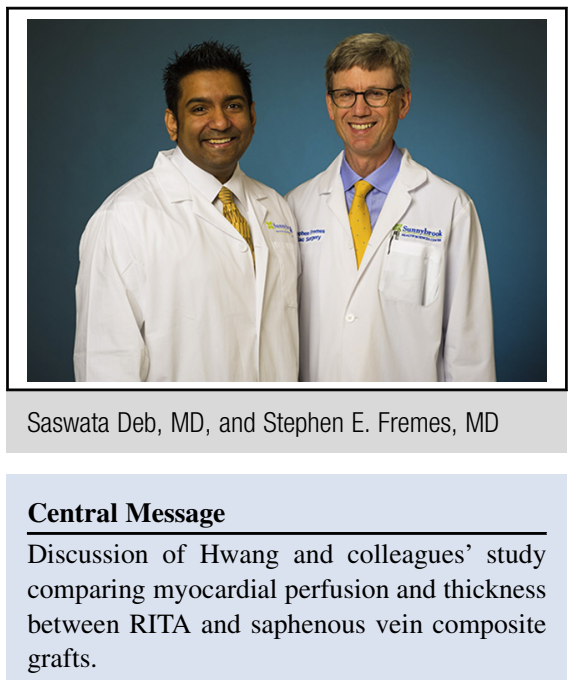

See Article page 1187.

at 3 months and 1 year after $\mathrm{CABG}$, as per their routine practice. The LITA was targeted to the left anterior descending territory, whereas the SVG or RITA (the second limb of the conduit) was used to revascularize first the lateral territory, followed by the inferior territory, by means of a sequential anastomosis technique. Hwang and colleagues $^{10}$ investigated changes in myocardial perfusion and segmental thickening. along with temporal and regional associations. The major findings of this study were that both myocardial perfusion and segmental thickening improved after surgery, and that these improvements were similar between the SVG and RITA groups at 1 year after surgery.

This study highlights some pertinent discussion points. Although in general, both the SVG and RITA cohorts had similar performance with respect to reversibility at 1 year after CABG, analysis by territory revealed that, in the right inferior territory, improvement in myocardial perfusion was less pronounced in the RITA group than in the group grafted with SVGs. One possible reason for this finding could be the smaller distal diameter of the RITA that is required to reach the right coronary target, which is more susceptible to spasm, as mentioned in the article. ${ }^{10}$ Another mechanistic cause could be the presence of competitive flow, which is often a problem with arterial grafts, especially in the right coronary territory. ${ }^{11}$ Glineur and colleagues $^{12}$ performed a randomized trial comparing grafting of the SVG, RITA (with a composite Y technique), and right gastroepiploic artery to the right coronary system and showed that SVG performed superiorly relative to the other arterial grafts at 3 years after $\mathrm{CABG} .{ }^{12}$ Their group 
has shown that competitive flow is more frequent with composite $\mathrm{Y}$ grafting in the right territory. ${ }^{11}$ Whereas the larger, nonresistant SVG fares well in this environment, the composite RITA grafting to the right territory may negatively remodel, ${ }^{11}$ especially in targets with lesser degree of proximal stenosis. ${ }^{13}$ This study did not account for proximal target stenosis, and the existence of these flow dynamic changes could explain the lessened perfusion improvement seen with RITAs than with SVGs. Furthermore, such changes could contribute to the lessened perfusion improvement seen in the right territory at 3 months relative to the LAD (temporally slower increase in perfusion).

In addition to perfusion, improvements in myocardial thickness were similar between the SVG and RITA groups. It has been shown that SVGs perform poorly relative to arterial grafts, ${ }^{14}$ especially in patients with diabetes. ${ }^{2}$ In the study of Hwang and colleagues, ${ }^{10}$ almost $50 \%$ of patients in the SVG cohort had diabetes; despite this, SVGs performed well. One reason for this could be the no touch atraumatic harvesting of the SVG. Relative to conventional skeletonized SVGs, which undergo manual dilation, SVGs harvested with the atraumatic no touch pedicled technique have been shown to have preservation of the endothelial layer and biochemical properties that are associated with decreased neointimal hyperplasia and atherosclerosis. ${ }^{15-17}$ Samano and colleagues ${ }^{18}$ conducted a randomized trial comparing no touch to conventional SVG harvesting in CABG with standard aortocoronary proximal anastomoses with longitudinal angiographic follow-up. In their most recent analysis, they reported that patency of no touch SVGs was comparable to patency of the LITA grafts at 16 years (conventional SVG, 64\%; no touch SVG, $83 \%$; LITA, $88 \%$ ).

The main strengths of the study of Hwang and colleagues $^{10}$ include its objective measurement of myocardial status and its advanced statistical analyses. Although angiographic and clinical outcomes are commonly reported in CABG studies, myocardial perfusion and segmental analysis are not. This study measures these variables by means of myocardial SPECT, which has been shown to be a strong predictive diagnostic tool for predicting cardiac death after CABG. ${ }^{19}$ Furthermore, advanced statistical analysis was performed involving mixed models, which accounted for repeated perfusion and thickness measurements in the same patients. Although this type of complex modeling was necessary, some of the results from these models, including certain interaction terms, were difficult to explain or may be spurious. Pertinent limitations of this study included the presence of biases associated with an observational study, along with selection bias because almost $50 \%$ of the SAVE RITA trial patients were excluded. Furthermore, target vessel characteristics, including target vessel size, quality and severity of target vessel stenosis, were not reported. Finally patients in whom a third conduit was required to reach a distal target were excluded, which was necessary in many more patients in the RITA group than in the SVG group.

Overall, Hwang and colleagues ${ }^{10}$ should be congratulated for this substudy, which required objective follow-up diagnostics as well as an advanced statistical approach. It highlights the concept that conduit selection for a specific target is an important consideration, especially for arterial grafts in the revascularization strategy. Moreover, as surgical revascularization is evolving with rapidly growing evidence for arterial grafting, this study serves as an encouraging reminder that even the historically used SVG grafts can perform well with the use of modern, atraumatic harvesting techniques like the no touch technique.

\section{References}

1. Buxton BF, Shi WY, Tatoulis J, Fuller JA, Rosalion A, Hayward PA. Total arterial revascularization with internal thoracic and radial artery grafts in triple-vessel coronary artery disease is associated with improved survival. J Thorac Cardiovasc Surg. 2014;148:1238-43; discussion 1243-4.

2. Deb S, Singh SK, Moussa F, Tsubota H, Une D, Kiss A, et al. The long-term impact of diabetes on graft patency after coronary artery bypass grafting surgery: a substudy of the multicenter Radial Artery Patency Study. J Thorac Cardiovasc Surg. 2014;148:1246-53; discussion 1253.

3. Bello SO, Peng EW, Sarkar PK. Conduits for coronary artery bypass surgery: the quest for second best. J Cardiovasc Med (Hagerstown). 2011;12:411-21.

4. Murphy DA, Hatcher CR Jr. Coronary revascularization in the presence of ascending aortic calcification: use of an internal mammary artery-saphenous vein composite graft. J Thorac Cardiovasc Surg. 1984;87:789-91.

5. Glineur D, Boodhwani M, Poncelet A, De Kerchove L, Etienne PY, Noirhomme P, et al. Comparison of fractional flow reserve of composite Y-grafts with saphenous vein or right internal thoracic arteries. J Thorac Cardiovasc Surg. 2010;140:639-45.

6. Gaudino M, Alessandrini F, Pragliola C, Luciani N, Trani C, Burzotta F, et al. Composite $\mathrm{Y}$ internal thoracic artery-saphenous vein grafts: short-term angiographic results and vasoreactive profile. J Thorac Cardiovasc Surg. 2004; 127:1139-44.

7. Davierwala PM, Leontyev S, Misfeld M, Rastan A, Holzhey D, Lehmann S, et al. No-touch aorta off-pump coronary bypass operation: arteriovenous composite grafts may be used as a last resort. Ann Thorac Surg. 2013;95:846-52.

8. Kim K-B, Hwang HY, Hahn S, Kim JS, Oh SJ. A randomized comparison of the Saphenous Vein Versus Right Internal Thoracic Artery as a Y-Composite Graft (SAVE RITA) trial: one-year angiographic results and mid-term clinical outcomes. Journal Thorac Cardiovasc Surg. 2014;148:901-7; discussion 907-8.

9. Hwang HY, Koo BK, Oh SJ, Kim KB. Morphologic changes of the saphenous vein Y-composite graft based on the left internal thoracic artery: 1-year intravascular ultrasound study. J Thorac Cardiovasc Surg. 2015;149:487-93.

10. Hwang HY, Paeng JC, Oh HC, Kim YH, Kim KB. Comparison of myocardial perfusion and thickening improvement between saphenous vein and right internal thoracic artery composite grafts: results from patients enrolled in a randomized controlled trial. J Thorac Cardiovasc Surg. 2015; 150:1187-94.

11. Glineur D, Hanet C. Competitive flow in coronary bypass surgery: is it a problem? Curr Opin Cardiol. 2012;27:620-8.

12. Glineur D, D'Hoore W, de Kerchove L, Noirhomme P, Price J, Hanet C, et al. Angiographic predictors of 3-year patency of bypass grafts implanted on the right coronary artery system: a prospective randomized comparison of gastroepiploic artery, saphenous vein, and right internal thoracic artery grafts. J Thorac Cardiovasc Surg. 2011;142:980-8.

13. Sabik JF III, Lytle BW, Blackstone EH, Khan M, Houghtaling PL, Cosgrove DM. Does competitive flow reduce internal thoracic artery graft patency? Ann Thorac Surg. 2003;76:1490-6; discussion 1497.

14. Desai ND, Cohen EA, Naylor CD, Fremes SE. Radial Artery Patency Study Investigators. A randomized comparison of radial-artery and saphenous-vein coronary bypass grafts. N Engl J Med. 2004;351:2302-9. 
15. Sepehripour AH, Jarral OA, Shipolini AR, McCormack DJ. Does a 'no-touch' technique result in better vein patency? Interact Cardiovasc Thorac Surg. 2011;13:626-30.

16. Dashwood MR, Tsui JC. 'No-touch' saphenous vein harvesting improves graft performance in patients undergoing coronary artery bypass surgery: a journey from bedside to bench. Vascul Pharmacol. 2013;58:240-50.

17. Verma S, Lovren F, Pan Y, Yanagawa B, Deb S, Karkhanis R, et al. Pedicled notouch saphenous vein graft harvest limits vascular smooth muscle cell activation: the PATENT saphenous vein graft study. Eur J Cardiothorac Surg. 2014;45:717-25.
18. Samano N, Geijer H, Liden M, Fremes S, Bodin L, Souza D. The no-touch saphenous vein for coronary artery bypass grafting maintains a patency, after 16 years, comparable to the left internal thoracic artery: a randomized trial J Thorac Cardiovasc Surg. 2015;150:880-8.

19. Zellweger MJ, Lewin HC, Lai S, Dubois EA, Friedman JD, Germano G, et al When to stress patients after coronary artery bypass surgery? Risk stratification in patients early and late post-CABG using stress myocardial perfusion SPECT: implications of appropriate clinical strategies. J Am Coll Cardiol. 2001;37: 144-52. 